\title{
An on-line laboratory in cognition and perception
}

\author{
IRA FISCHLER \\ University of Florida, Gainesville, Florida 32611
}

\begin{abstract}
The design of a computer-based laboratory system requires the coordination of pedagogical and technical goals. The development of our on-line laboratory in cognition and perception is described. The laboratory consists of 11 on-line experiments in which the student participates as both experimenter and subject. The software was designed for maximum transportability: Programs were written in a low-level BASIC, with thorough documentation; flexibility is provided both within and across experiments to suit local constraints; and the experiments are supported by a student manual, instructor's manual, and implementation notes. Criteria for selecting experiments, implementation of the experiments, and preliminary evaluation of the laboratory are discussed.
\end{abstract}

The advantages of using computers in laboratory settings have been described before, as have the reasons why cognitive psychology is particularly well suited to on-line experimentation and instruction (see, for example, Keenan \& Keller, 1980). These arguments have not been lost on academic psychologists. One indication of this was at an open-house introductory workshop for the use of on-line microcomputers in science instruction that was recently held within the Pima County Community College system. Although the sponsors had prepared primarily for the "natural" sciences, the majority of those attracted were experimental psychologists (Robson, Note 1). Rather than review these arguments, I would like to describe some of the pedagogical and technical considerations that have gone into the development of a particular on-line laboratory in cognition and perception (Levy, Fischler, \& Griggs, 1979), consider the extent to which technical constraints might influence instructional goals, and evaluate the laboratory as it is now in use.

\section{PRELIMINARY DECISIONS}

\section{Who Does What?}

On-line systems can involve three basically different kinds of educational activities. The first is instruction; teaching of material with computer technology (CAI) may be more effective than using a human instructor (e.g., Millward, 1979). The second is on-line experimentation, with the computer providing the presentation of stimuli and recording of responses. The third and perhaps most powerful activity is the generation of simulated data given a model of a task and specification

The development of the laboratory described here was supported by a National Science Foundation for Local Curriculum Improvement (LOCI) Grant SER 77-2036. Reprint requests may be sent to the author at the Department of Psychology, University of Florida, Gainesville, Florida 32611. of the models' parameters. We decided that a division of labor among computer, instructor, and text materials would provide the greatest flexibility for adoption of the laboratory elsewhere. The software was therefore designed primarily as a series of on-line experiments, with sufficient direction to the student at the terminal to get through the experiment without the aid of an instructor, and to provide some hard-copy data. The full background of ideas and concepts behind the experiments, and the description of models to which the students may try to fit their data, is the joint responsibility of the student manual and the instructor. How this is done will be described in detail later as we consider one particular experiment.

\section{Range of Topics}

Over the past 10 years, we have found the content of typical courses, and texts, in cognitive psychology to have become fairly consistent in the range and progression of topics and, therefore, of experiments. Current texts (e.g., Bourne, Dominowski, \& Loftus, 1979) devote the first half of coverage to the basic "information processing system," including topics such as pattern recognition, attention, and short- and long-term memory. In the second half, this "system" analysis is applied to more complex mental processes: concept learning, thinking, and problem solving. The experiments in our laboratory were intended to reflect both the range and particular progression of topics now commonly found in these texts. While the experiments can be used in more narrowly defined and/or advanced classes, and the order in which the experiments are carried out is not highly constrained, the laboratory in its entirety was designed to parallel the contemporary course in cognitive psychology. Thus, principles developed in the initial experiments are carried over as a framework in which to describe later experiments as students are led from computing thresholds to estimating parameters of complex tasks. The framework in which we selected experiments is shown in Table 1. 
Table 1

Outline of Experiments in the On-Line Laboratory

\begin{tabular}{|c|c|}
\hline Topic & Paradigm \\
\hline $\begin{array}{l}\text { Psychophysics } \\
\text { Method of Constant Stimuli } \\
\text { Signal Detection }\end{array}$ & $\begin{array}{l}\text { Mueller-Lyer Illusion } \\
\text { Vigilance }\end{array}$ \\
\hline $\begin{array}{l}\text { Sensory Memory } \\
\text { Span of Apprehension } \\
\text { Iconic Memory }\end{array}$ & $\begin{array}{l}\text { Letter Array, Whole Report } \\
\text { Letter Array, Partial Report (Sperling) }\end{array}$ \\
\hline $\begin{array}{l}\text { Pattern Recognition } \\
\text { Feature Detection } \\
\text { Pattern Interpretation }\end{array}$ & $\begin{array}{l}\text { Visual Search, Letters (Neisser) } \\
\text { Letter Pairs, Physical or Name Matching (Posner) }\end{array}$ \\
\hline $\begin{array}{l}\text { Short-Term Memory } \\
\text { Retrieval from STM } \\
\text { Short-Term Forgetting }\end{array}$ & $\begin{array}{l}\text { Digit Classification (Sternberg) } \\
\text { Distractor Task (Peterson \& Peterson) }\end{array}$ \\
\hline $\begin{array}{l}\text { Information Processing } \\
\text { Comparing Visual and Semantic Information }\end{array}$ & Picture-Sentence Comparison (Chase \& Clark) \\
\hline $\begin{array}{l}\text { Thinking } \\
\text { Concept Learning } \\
\text { Reasoning from Prose }\end{array}$ & $\begin{array}{l}\text { Blank-Trials Classification (Levine) } \\
\text { Set Inclusion (Potts, Griggs) }\end{array}$ \\
\hline
\end{tabular}

\section{Choice of Experiments}

Table 1 also shows the particular paradigms selected for the laboratory. One of our primary criteria for selection was that the experiment be based on a seminal study that highlighted an important aspect of human information processing and evoked a large literature using the same or a similar paradigm. At this level, knowledge of both the content of these experiments and the methodology is included in our educational goals.

We also sought studies with clearly defined, comprehensible issues, such as the problem of bias in signal detection, the fate of short-term memory, and the distinction between serial and parallel processing. A further criterion was that the results include some outcomes that were intuitive and others (such as the rapid loss of information in the short-term memory experiment of Peterson \& Peterson, 1959) that were quite surprising to the novice. As Keenan and Keller (1980) agree, this is very helpful in generating interest in the theoretical issues dealt with by experiments.

Finally, experiments were favored that allowed us to stress the development of experimental skills of the students in the areas of design, methodology, and analysis. Although no formal exposure to design or statistics is included in the package, each study offers a variety of options that reflect the choices the experimenter must make in getting from the conception to the experiment. In several studies, the student may choose between within-subjects and between-subjects designs, and in all cases he is asked to consider what difference design choices might make in the analysis or interpretation of results. The student also can choose between alternative conditions or materials, such as whether consonant trigrams or word triplets are used in shortterm memory study. The student also specifies a number of procedural parameters for some of the experiments. For example, they select the duration of the array and the delay between array and cue in the experiment on iconic memory.

Less emphasis was placed on statistical analysis than on experimental design, but most of the experiments chosen allow for a choice of relatively straightforward analyses, from $t$ tests to one- and two-way ANOVAs. Choice of statistics is left to the instructor, and the success of the laboratory is not dependent on a high level of statistical skill among the students. We could expect, on the contrary, that exposure to problems of within-condition variability in their own data would better prepare the students for the study of statistics.

\section{IMPLEMENTATION}

\section{Technical Factors as an Educational Device}

One would hope that the technical realities of computing systems would not place great constraints on the selection of experiments for a laboratory package. Although we may have unintentionally focused on "programmable" paradigms from the start, we found few unsurmountable obstacles to implementing on the computer CRT paradigms that were chosen for educational value. A modest amount of creativity solved most of our problems. For example, it was unreasonable to use the counting-backward task as did Peterson and Peterson (1959) in the study of short-term memory, given that as many as 10 students would be muttering numbers in the same room, so a speeded numerical judgment task was substituted. Often, these pragmatic variations had an educational benefit: In most cases, the study as realized on the CRT differed in a variety of ways from the original, which raised some interesting theoretical questions of which the student could be 
made aware. In general, this turned a technological problem into a lesson for young researchers: "How are you constrained by your equipment?"

\section{The Problem of Time Control}

As with most computer-based, multistation experimental laboratories, the need for precise control of stimulus timing and accurate measurement of latencies created some difficulties (cf. Bewley, 1974). Our laboratory was initially implemented in multiuser BASIC, under RT -11 on a PDP-11/34. The slow execution time of BASIC statements and the round-robin polling of terminals created unacceptable lags in certain of the programs requiring precise timing of stimulus events and recording of latencies. Creating an assembly-level call to handle precise timing produced better resolution, but it required that the processor be captured by whatever terminal had made the call. Care had to be taken, then, in monitoring which studies were being executed simultaneously.

The progressive reductions in the cost of high-level microcomputer systems led to our adoption of independent, dedicated machines for the laboratory. We now have 10 microcomputer stations, each with a floppy disk drive. A common line printer provides hard copies of the data obtained by each student in a given experiment. The duplication of hardware is more than counterbalanced, we feel, by the freedom from peculiar interaction between users, from necessity for down-line local additions to hardware for timing purposes, and from the risks of the master system going down for substantial amounts of time in the middle of a course.

\section{Transportability}

From the start of our efforts, the laboratory has been designed with maximum transportability as an important criterion. The programs were written in BASIC with as few dialect-specific features as possible. The limits of transportability come more in the CRT requirements. The need for rapid transmission $(9,600$ baud) virtually eliminates most campuswide timesharing systems (see Friendly \& Franklin, 1979), unless a screen-blanking facility is available. The system must have programmable cursor control, some type of TIME function, and the ability to react to a single character input at the keyboard without RETURN being pressed [in MU BASIC, this is the SYS (4) function].

\section{A SAMPLE EXPERIMENT}

Following a particular experiment in some detail will provide a better feeling for what the student is actually doing in the laboratory. In our (Levy et al., 1979) Experiment 8, "Forgetting from STM," the loss of the ability to recall a stimulus over a brief interval filled with a distracting task is measured. Background material may have been obtained in lecture courses, but we make no assumptions about prior knowledge. The student first reads the introduction to the experiment in the student manual, which consists of an overview of the Peterson and Peterson (1959) experiments, introducing the idea of rehearsal and the importance of preventing it in the study of short-term forgetting. The purposes of the experiment are enumerated, and the design of the study is explained. It is noted that there are two independent variables: type of material studied (consonants or words) and retention interval $(3-18 \mathrm{sec})$. The interval is varied within subjects, and the instructor has the option of within- or between-subjects designs for the type of material. The manual also describes the procedure of the on-line experiment and tries to anticipate any problems or confusions that might arise. This preparation is extremely important for getting students smoothly through the on-line study, no matter how explicit the program is made. In this case, we take some time in describing the distractor task, and how the student might approach it. We also stress the need for precision in entering the response on the keyboard. (This turns out to be nontrivial; we found it important to keep the student's interaction with the keyboard to a minimum.)

The on-line experiment itself consists of a brief overview of the nature of the experiment and a description of the procedure to be followed. The student then selects the type of material to be used and the maximum time to be allowed for making each numerical judgment. A practice trial follows, after which the instructions can be reviewed. A series of 48 trials follows, with eight repetitions of each of six delay intervals, randomly presented. On each trial a to-be-recalled item is presented, followed by a series of three-digit numbers. The subject must categorize the number as greater or less than 500. A recall cue prompts the subject to type in the recalled stimulus; accuracy and latency are stored. The student then obtains a hard copy of his data from the printer.

The output includes the raw data for each trial, as well as a summary across trials for each retention interval. Data files can be stored across students for later distribution by the instructor for either group averages or comparison of individual differences. At this point, the student returns to the student manual for instructions on data description and analyses. A series of discussion questions tries to get the student to critically reflect upon the data. Here the questions include the following: Did words or letters produce better performance? Are the data similar to previous published work? Was there a relation between accuracy of recall and latency of recall? Was performance better on the first few trials than on later trials? All of these can serve as homework assignments, a basis for class discussions, or ideas for written reports and further experiments.

\section{EVALUATION}

Our evaluation of the laboratory has so far been limited to opinion surveys of the students, who almost without exception enjoy the laboratory. They like 
interacting with a computer and seeing its capabilities and feel they have gained an understanding both of the particular experiments and of experimental research in general. It is difficult to directly compare the on-line lab to earlier laboratories in terms of educational success. Too many other factors have changed over recent years to use such comparative measures as number of senior theses generated, quality of written lab reports, or graduate school admissions in a meaningful way. One form of evaluation is the performance of the laboratory itself: The programs work; the laboratory functions smoothly as a course each quarter we teach it; and the on-line model we chose has been adopted by our department for development of laboratories in areas ranging from physiological psychology to personality theory. But as Levy (1980) has pointed out, some formäl evaluation of the educational impact of on-line laboratories is part of the responsibility of those creating the systems. Since the laboratory in cognition and perception has been adopted by CONDUIT for national distribution, we hope to be able to do such evaluation over a more meaningful data base than we currently have available.

\section{REFERENCE NOTE}

1. Robson, J. Personal communication, July 1979.

\section{REFERENCES}

BEWLEY, W. Cognitive psychology. Iowa City, Iowa: CONDUIT, 1974.

Bounne, L. E., Dominowskı, R. L., \& Loftus, E. F. Cognitive processes. Englewood Cliffs, N.J: Prentice-Hall, 1979.

Friendly, M., \& Franklin, P. Computer control of memory experiments on a large-scale timesharing system. Behavior Research Methods \& Instrumentation, 1979, 11, 212-217.

Keenan, J. M., \& Keller, R. A. Teaching cognitive processes: Software for laboratory instruction in memory and cognition. Behavior Research Methods \& Instrumentation, 1980, 12, 103-110.

LEvy, C. M. Getting an on-line departmental teaching laboratory on-line. Behavior Research Methods \& Instrumentation, 1980, 12, 111-113.

Levy, C. M., Fischler, I., \& Griggs, R. A. Laboratory in cognition and perception. Iowa City, Iowa: CONDUIT, 1979.

Millward, R. Teaching a computer to teach. Behavior Research Methods \& Instrumentation, 1979, 11, 102-110.

Peterson, L. R., \& Peterson, M. J. Short-term retention of individual items. Journal of Experimental Psychology, 1959, 58, 193-198. 